\title{
Combating the Methamphetamine Epidemic: Education alone is Insufficient
}

\author{
Rick AMP ${ }^{1 *}$, Paul $\mathbf{W}^{2}$, Nhan $\mathrm{HD}^{3}$, Geoffrey $\mathbf{K}^{1}$, Francisco $\mathbf{M}^{4}$, Gregory $\mathbf{M}^{4}$, \\ Tuan $\mathrm{AN}^{4}$ and Nicole $\mathrm{VL}^{4}$ \\ ${ }^{1}$ Department of Emergency Medicine, Kern Medical, Bakersfield, CA, USA \\ ${ }^{2}$ Department of Pediatric Emergency Medicine, Sutter Medical Center, Sacramento CA, USA \\ ${ }^{3}$ Department of Emergency Medicine, Riverside Community Hospital, Riverside, CA, USA \\ ${ }^{4}$ Emergency Medicine Research Assistant Program at Kern Medical, Bakersfield, CA, USA
}

\section{Research Article \\ Volume 4 Issue 1}

Received Date: March 23, 2020

Published Date: June 12, 2020

DOI: $10.23880 /$ phoa-16000152

*Corresponding author: Rick McPheeters DO, Department of Emergency Medicine, Kern Medical/ UCLA, 1700 Mt. Vernon Ave, Bakersfield, CA 93306, USA, Email: Rick.Mcpheeters@kernmedical.com

\section{Abstract}

Objectives: As in many other areas of the country, methamphetamine use and dependence has been perceived by [blinded for peer review] County as a significant and progressively worsening, yet unmeasured scourge to the community. In an attempt to combat this epidemic, [blinded for peer review] County decided to study the efficacy of education on diminishing the impact of methamphetamine on our community. Our goal was to study the prevalence of methamphetamine use in patients seeking emergency medical care and what impact, if any, education would have.

Methods: As a part of a county-wide program in [blinded for peer review] County to study the impact of methamphetamine use on our community, a cross-sectional study in 2008 measured the prevalence of methamphetamine use as well as other epidemiologic factors of the users in our emergency department. An educational campaign was subsequently launched across the county and focused primarily on raising public awareness in order to prevent abuse and recruit more abusers into existing treatment programs. The educational campaign targeted businesses, media, family-wellbeing, and school-aged children. A post-intervention study was once again conducted in 2014 to assess the effectiveness of the educational campaign.

Results: Between 2008 and 2014, the prevalence of patients who self-reported methamphetamine usage at least once during their lifetime remained relatively unchanged at 31.5\% (107/340, 95\% CI: $26.8 \%-36.6 \%)$ vs. 31.8\% (55/173, 95\% CI: 25.3\%-39.1\%) respectively. The largest group admitting to having used methamphetamine in both surveys was Caucasian males in the 26-45 year old category. The only difference seen between the two years was a decrease in the prevalence of methamphetamine users having sought treatment $(42 / 107,39.3 \%$ to $15 / 55,27.3 \%, p=0.3)$. However, this change was not statistically significant.

Conclusion: Education alone is likely insufficient to affect the prevalence of methamphetamine use. In the future, a multifaceted approach including a greater emphasis on treatment and rehabilitation programs will likely be more effective. In addition, future studies aimed specifically at populations at risk of methamphetamine abuse may give us a deeper understanding of this epidemic.

Keywords: Methamphetamine; Symptomatic; Related Organ System 


\section{Introduction}

The harmful effects of methamphetamine use are well known to most members of the medical community [1-6]. As in many other areas of the country, methamphetamine use and dependence has been perceived by [blinded for peer review] as significant and progressively worsening, yet unmeasured scourge to the community for many years [1,7-16]. In 2007, a federal grant was given to [blind for peer review] Mental Health department to evaluate the actual socioeconomic impact on the county's resources and agencies. As a part of this, [blinded for peer review] conducted a cross sectional study in 2008 to measure the initial prevalence of methamphetamine use in patients presenting to the emergency department. Following this county-wide study conducted by multiple law enforcement agencies, the fire department, mental health department, and [blinded for peer review], which showed significant rates of methamphetamine use across all departments, the [blinded for peer review] County Methamphetamine Reduction Task Force was created with the goal of reducing the prevalence of abuse and dependence on this substance in [blinded for peer review]. An educational campaign was launched and focused primarily on raising public awareness in order to prevent abuse and recruit more abusers into existing treatment programs. The campaign targeted four main areas.

- Businesses were educated regarding the benefits of identifying drug use in the work place and guidelines for maintaining a drug-free work place.

- A media campaign was launched to increase awareness and encourage reporting in the community.

- Family wellbeing programs were developed to increase awareness of risk and protective factors for methamphetamine use.

- Social marketing campaign aimed at school aged children to address youth drug use as well as the expansion of prevention and intervention programs in schools. Subsequently, a post intervention survey was performed again in 2014 as a part of a county wide study in order to assess the impact of the educational campaign on rates of methamphetamine use in [blinded for peer review]. We hypothesized that the prevalence of methamphetamine usage would be decreased between 2008 and 2014 .

\section{Methods}

After obtaining IRB approval, a cross-sectional survey study was performed at [blinded for peer review]'s emergency department. [Blinded for peer review] is a level II trauma center with a yearly census of approximately 45,000 patients, serving an urban and rural population. Patients were enrolled between May 10 through June 10 in 2008 and June 1 through June 30 in 2014. A block randomization method was used with research assistants rotating among day, evening, and night shifts in order to ensure generalization of the population of [blinded for peer review]'s emergency department. However because of funding issues in 2014, the number of research assistants that could be hired to collect data was significantly less and led to a smaller sample size in that year. Patients in the proximity of law enforcement officers were excluded from the study. Minors were also excluded from the study due to IRB guidelines. Patients were interviewed in private and voluntarily reported information regarding their history of methamphetamine use as per a questionnaire which included: the patient's gender, ethnicity, and age; whether or not they have ever used methamphetamines in their lives; and whether or not they have ever sought treatment. In addition, the attending emergency department physicians were also surveyed regarding whether or not they suspected involvement of methamphetamines in the patient's case. The acuity level of visitation was also recorded.

The levels of visitation were defined as follows:

- Level I: Limited examination of the affected organ system.

- $\quad$ Level II \& III: Limited examination of the affected area or organ system and other symptomatic or related organ system(s).

- Level VI: Extended examination of the affected area or organ system and other symptomatic or related organ system(s).

- Level V: General multi-system examination or a complete examination of a single organ system.

\section{Results}

\section{Data}

Of the 340 patients who participated in the study in 2008, 107 patients answered "yes" to having used methamphetamines in their lives. This reflects a prevalence of $31.5 \%$ ( 95\%CI $26.8 \%-36.6 \%$ ). $39.6 \%$ of the patients who admitted to using methamphetamines stated that they had spent time in drug rehabilitation treatment. Emergency department physicians suspected methamphetamine use in only $4.8 \%$ of these patients. Males were more likely to use than females (Table 1), and Caucasians were the predominant ethnicity (Tables 2-8) (Figures 1-4). 
Public Health Open Access

\begin{tabular}{|c|c|c|c|}
\hline & $\operatorname{Male}(n=185)$ & Female(n=151) & $\operatorname{Unknown}(n=4)$ \\
\hline$\%$ of total patients, $n=340$ & 54.4 & 44.4 & 1.2 \\
\hline$\%$ of meth-involved patients, $n=107$ & 66.4 & 32.7 & 0.9 \\
\hline$\%$ of group that reported usage & 38.4 & 23.2 & 25 \\
\hline
\end{tabular}

Table 1: 2008, all study participants by gender.

\begin{tabular}{|c|c|c|c|c|c|}
\hline & $\begin{array}{c}\text { African American } \\
(\mathbf{n = 3 7 )}\end{array}$ & $\begin{array}{c}\text { Asian/Pacific } \\
\text { Islander (n=9) }\end{array}$ & $\begin{array}{c}\text { Hispanic } \\
(\mathbf{n = 1 6 1})\end{array}$ & $\begin{array}{c}\text { White } \\
(\mathbf{n = 1 2 5})\end{array}$ & $\begin{array}{c}\text { Unknown } \\
(\mathbf{n = 8})\end{array}$ \\
\hline \% of total patients, $\mathrm{n}=340$ & 10.9 & 2.6 & 47.4 & 36.8 & 2.4 \\
\hline \% of meth-involved patients, $\mathrm{n}=107$ & 3.7 & 0.9 & 41.1 & 49.5 & 4.7 \\
\hline \% of group that reported usage & 10.8 & 11.1 & 27.3 & 42.4 & 62.5 \\
\hline
\end{tabular}

Table 2: 2008, all study participants by race/ethnicity.

\begin{tabular}{|c|c|c|c|c|c|}
\hline & $\mathbf{1 8 - 2 5}(\mathbf{n = 7 3 )}$ & $\begin{array}{c}\mathbf{2 5 - 4 5} \\
(\mathbf{n = 1 2 1})\end{array}$ & $\begin{array}{c}\mathbf{4 6 - 6 4} \\
(\mathbf{n = 1 2 6})\end{array}$ & $\begin{array}{c}\mathbf{6 5} \text { and older } \\
(\mathbf{n = 1 7})\end{array}$ & Unknown(n=3) \\
\hline \% of total patients, $\mathrm{n}=340$ & 21.5 & 35.6 & 37.1 & 5 & 0.9 \\
\hline \% of meth-involved patients, $\mathrm{n}=107$ & 15 & 45.8 & 37.4 & 1.9 & 0.0 \\
\hline \% of group that reported usage & 21.9 & 40.5 & 31.7 & 11.8 & 0.0 \\
\hline
\end{tabular}

Table 3: 2008, all study participants by age.

\begin{tabular}{|c|c|c|c|c|c|c|}
\hline & I (n=25) & $\begin{array}{c}\text { II } \\
(\mathbf{n = 6 2})\end{array}$ & $\begin{array}{c}\text { III } \\
(\mathbf{n = 1 2 4})\end{array}$ & $\begin{array}{c}\text { IV } \\
(\mathbf{n = 7 3 )}\end{array}$ & $\begin{array}{c}\text { V } \\
(\mathbf{n = 4 1})\end{array}$ & $\begin{array}{c}\text { Unknown } \\
(\mathbf{n = 3})\end{array}$ \\
\hline \% of total patients, $\mathrm{n}=340$ & 7.4 & 18.2 & 36.5 & 21.5 & 12.1 & 4.4 \\
\hline \% of meth-involved patients, $\mathrm{n}=107$ & 8.4 & 19.6 & 32.7 & 23.4 & 13.1 & 2.8 \\
\hline \% of group reporting usage & 36 & 33.9 & 28.2 & 34.2 & 34.1 & 100 \\
\hline
\end{tabular}

2014 data: In 2014, 173 patients participated and 55 answered "yes," reflecting a 31.8\% prevalence (95\% CI 25.3\%-39.1\%). $27.3 \%$ of the patients who reported methamphetamine use also reported drug rehabilitation.

Table 4: 2008, all study participants by level of visitation.

\begin{tabular}{|c|c|c|c|}
\hline & Male $(\mathbf{n = 8 9})$ & Female $(\mathbf{n = 8 2})$ & Unknown (n=2) \\
\hline \% of total patients, $\mathrm{n}=173$ & 51.4 & 47.4 & 1.2 \\
\hline \% of meth-involved patients, $\mathrm{n}=55$ & 70.9 & 27.3 & 1.8 \\
\hline \% of group that reported usage & 43.8 & 18.3 & 50 \\
\hline
\end{tabular}

Table 5: 2014, all study participants by gender.

\begin{tabular}{|c|c|c|c|c|c|c|}
\hline & $\begin{array}{c}\text { African } \\
\text { American (n=22) }\end{array}$ & $\begin{array}{c}\text { Asian/Pacific } \\
\text { Islander (n=6) }\end{array}$ & $\begin{array}{c}\text { Hispanic } \\
(\mathbf{n = 7 4 )}\end{array}$ & $\begin{array}{c}\text { White } \\
(\mathbf{n = 5 8})\end{array}$ & $\begin{array}{c}\text { Other } \\
(\mathbf{n = 1 2})\end{array}$ & $\begin{array}{c}\text { Unknown } \\
(\mathbf{n = 1})\end{array}$ \\
\hline \% of total patients, n=173 & 12.7 & 3.5 & 42.8 & 33.5 & 6.9 & 0.6 \\
\hline \% of meth-involved patients, n=55 & 3.6 & 0 & 40 & 47.3 & 9.1 & 0 \\
\hline \% of group that reported usage & 9.1 & 0 & 29.7 & 44.8 & 41.7 & 0 \\
\hline
\end{tabular}

Table 6: 2014, all study participants by race/ethnicity. 
Public Health Open Access

\begin{tabular}{|c|c|c|c|c|}
\hline & $\mathbf{1 8 - 2 5}(\mathbf{n = 3 1})$ & $\mathbf{2 5 - 4 5}(\mathbf{n = 7 0})$ & $\mathbf{4 6 - 6 4}(\mathbf{n = 6 6})$ & $\mathbf{6 5}$ and older $(\mathbf{n = 6})$ \\
\hline \% of total patients, $\mathrm{n}=173$ & 17.9 & 40.5 & 38.2 & 3.5 \\
\hline \% of meth-involved patients, $\mathrm{n}=55$ & 10.9 & 45.5 & 41.8 & 1.8 \\
\hline \% of group that reported usage & 19.4 & 35.7 & 34.8 & 1.7 \\
\hline
\end{tabular}

Table 7: 2014, all study participants by age.

\begin{tabular}{|c|c|c|c|c|c|c|}
\hline & I (n=6) & II (n=18) & III (n=90) & IV(n=45) & V (n=11) & Unknown (n=3) \\
\hline \% of total patients, $\mathrm{n}=173$ & 3.5 & 10.4 & 52 & 26 & 6.4 & 1.7 \\
\hline \% of meth-involved patients, $\mathrm{n}=55$ & 0 & 12.7 & 54.5 & 27.3 & 3.6 & 1.8 \\
\hline \% of group reporting usage & 0 & 38.9 & 33.3 & 33.3 & 18.1 & 33.3 \\
\hline
\end{tabular}

Table 8: 2014, all study participants by level of visitation.

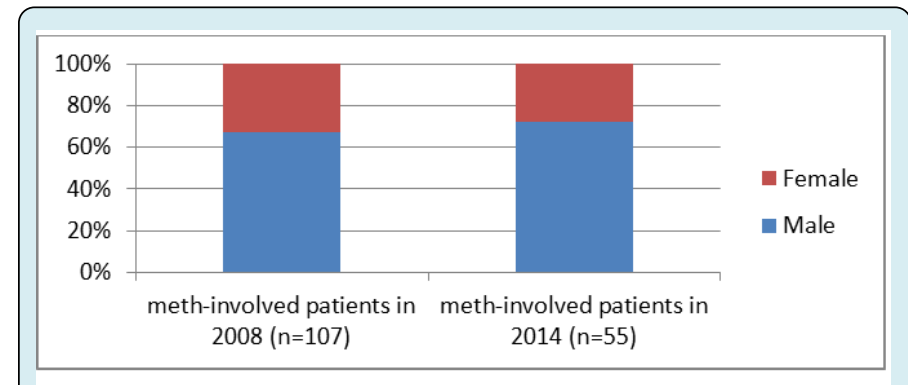

Figure 1: Comparison of 2008 vs. 2014, by gender.

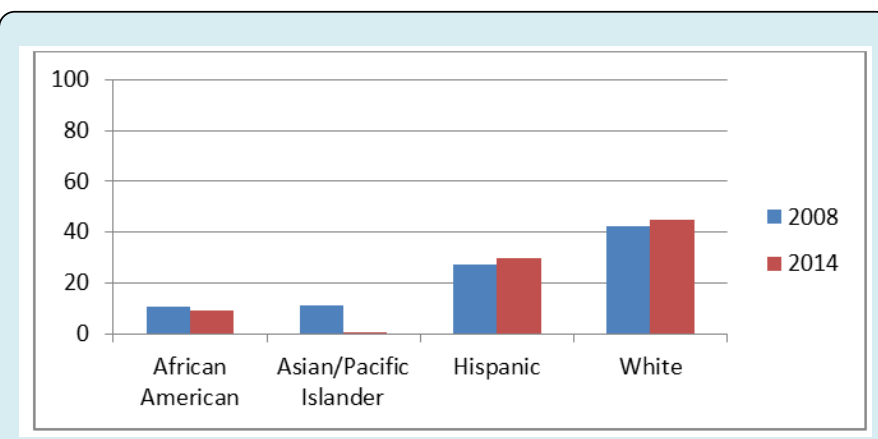

Figure 2: Comparison of 2008 vs. 2014, percentage reporting meth-usage by race/ethnicity.

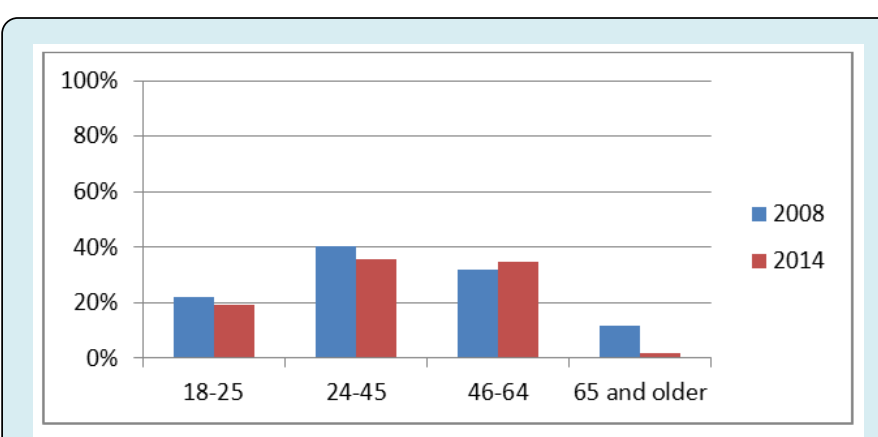

Figure 3: Comparison of 2008 vs. 2014, percentage reporting meth-usage by age group.

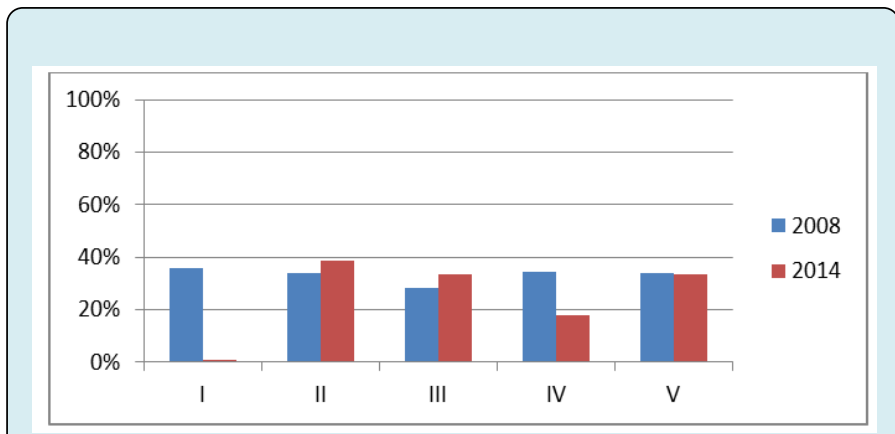

Figure 4: Comparison of 2008 vs. 2014, percentage reporting meth-usage by level of visitation.

\section{Discussion}

Our results highlighted that there was no statistically significant change in the prevalence of methamphetamine usage between 2008 and 2014. Although our study lacked power, our results echoed those found by all other [blinded for peer review] County departments and agencies involved in the initiative. This strongly suggests that in order to have a significant impact on methamphetamine usage, it will likely require more than merely raising public awareness.

However, despite the lack of change in prevalence of methamphetamine usage, the study gave us good insight into the demographics of our population who used methamphetamines which will likely be helpful in the future combating the methamphetamine epidemic. We found that the majority of our methamphetamine users were Caucasian males in the 26-45 year old category. In both years, the 26-45 year old group and the 46-64 year old group were disproportionately more likely to use methamphetamine than all other age groups. Though Caucasians and Hispanics were the most highly represented groups in the participants enrolled in both 2008 and in 2014, Caucasians had a disproportionately higher rate of methamphetamine usage compared to all other ethnicities. Surprisingly, level of 


\section{Public Health Open Access}

visitation did not seem to be affected by methamphetamine usage, as is seen by its relatively consistent prevalence in all levels in 2008. In 2014, there appeared to be more variance among prevalence when compared to level of visitation, but this was thought to be due to the smaller sample size that was obtained in that year. In addition, there was a trend towards fewer enrollments into rehabilitation programs.

\section{Limitations}

Besides the much smaller sample size obtained in 2014 in comparison to 2008, our study had other notable limitations. The study obtained data which was selfreported and therefore may not reflect the true prevalence of methamphetamine-usage in our population. Because of the nature of the study and IRB guidelines regarding minors, we were unable to enroll patients under the age of 18 into our study. This would have given us excellent insight into the age group that is thought to be the most impressionable, and therefore education would most likely impact this age group the greatest. In addition, while the study obtained data on whether or not patients have used methamphetamines, it did not assess current usage and frequency of usage.

\section{Conclusion}

The county wide educational campaign did not appear to have any impact on the prevalence of methamphetamine usage in patients seeking emergency medical services at [blinded for peer review]. Although the importance of education cannot be stressed enough, our data suggested that it alone cannot combat this epidemic. However, we believe our study has an important place in the literature because at this time, studies on affecting methamphetamine prevalence on a community level remains very limited.

In the future, this may lead to a paradigm shift on how to affect drug abuse in our community where a multifaceted approach may be more effective in combating the methamphetamine epidemic. Given the demonstrated benefit of treatment programs in methamphetamine dependent individuals, a greater emphasis on and increased funding in rehabilitation and treatment may be indicated to affect the rates of usage in our community as a whole. In addition, further evaluation and reform of the county's rehabilitation programs to include evidenced-based approaches such as medication-assisted methods may prove helpful [17]. Moreover, because of methamphetamine's stimulating effect on the mind and body, its usage among [blinded for peer review] County's large blue-collar population as well as student population should also be evaluated and addressed. Finally, future plans of our community should aim to target the population which our study has shown to be most at risk of usage.

\section{References}

1. Cartier J, Farabee D, Prendergast M (2006) Methamphetamine Use, Self-reported Violent Crime and Recidivism Among Offenders in California Who Abuse Substances. J Interpers Violence 21(4): 435-445.

2. Chang L, Ernst T, Speck O, Grob CS (2005) Addictive Effects of HIV and Chronic Methamphetamine Use on Brain Metabolic Abnormalities. Am J Psychiatry 162(2): 361-369.

3. Huber A, Ling W, Shoptaw S, Gulati V, Brethen P, et al. (1997) Integrating Treatments for Methamphetamine Abuse: A Psychosocial Perspective. J Addict Dis 16(4): 41-50.

4. Kuhn C, Scott S, Wilson W (2009) Buzzed: The Straight Facts About the Most Used and Abused Drugs from Alcohol to Ecstasy. $3^{\text {rd }}$ [Edn.], Ulster Med J 78(3): 204205.

5. National Institute on Drug Abuse (2006) Methamphetamine Abuse and Addiction, US Department of Health and Human Services, NIH Publication number, pp: 4206-4210.

6. Volkow ND, Linda C, Gene JW, Joanna SF, Maria LY, et al. (2001) Association of Dopamine Transporter Reduction with Psychomotor Impairment in Methamphetamine Abusers. Am J Psychiatry 158: 377-382.

7. Phillip B, Amanda P, Jason Z (2007) The Vortex: The Concentrated Racial Impact of drug Imprisonment and the Characteristics of Punitive Counties. Justice Policy Institute, pp: 1-36.

8. Caroline JA (1996) Hep-Cats, Narcs, and Pipe Dreams: A History of America's Romance with Illegal Drugs. NY: Scribner. Journal of Social History 33(1): 179-183.

9. Kane WK, Janicheck J, Cooley T, Grimmer A, Enoch K, et al. (2007) The Illinois Consortium on Drug Policy: Through a different lens: shifting the focus on Illinois drug policy, pp: 1-82.

10. Kane WK, Janicheck J, Clark D (2007) The Illinois Consortium on Drug Policy: Intersecting Voice: impacts of Illinois' drug policy, pp: 1-72.

11. (2007) Evaluation of the Substance Abuse and Crime Prevention Act Final Report. Department of Alcohol and Drug Programs California Health and Human Services Agency.

12. (2006) The Meth Epidemic in America: Two new Surveys 
of US Counties.

13. (2006) The Meth Epidemic in America: The Criminal Effect of Meth on Communities.

14. (2006) Office of National Drug Control Policy.

15. (2006) Drug Abuse Warning network: National Estimates of Drug-Related Emergency Department Visits, 200420011-All Visits. SAMHSA.
16. Swanson SM, Sise CB, Michael JS, Daniel IS, Troy LH, et al. (2007) The Scourge Of Methamphetamine: Impact On Level 1 Trauma Center. J Trauma 63(3): 531-537.

17. Richard AR, Patricia MC, Douglas MA, Alice D, Yvonne F, et al. (2004) A Multi-Site Comparison of Psychosocial Approaches for the Treatment of Methamphetamine Dependence. Addiction 99(6): 708-717. 